\title{
Corrigendum: Mental State Understanding and Moral Judgment in Children with Autistic Spectrum Disorder
}

\author{
Francesco Margoni and Luca Surian * \\ Department of Psychology and Cognitive Sciences, University of Trento, Rovereto, Italy
}

Keywords: moral judgment, mental state understanding, theory of mind, autism spectrum disorders, moral development

\section{A corrigendum on}

Mental State Understanding and Moral Judgment in Children with Autistic Spectrum Disorder by Margoni, F., and Surian, L. (2016). Front. Psychol. 7:1478. doi: 10.3389/fpsyg.2016.01478

We realized that Figure 1 was misleading. The figure showed the mechanisms underlying the moral judgment of attempted harm cases in individuals with autistic spectrum disorder (ASD). However, it would be more in line with the current studies, that primarily presented ASD individuals with cases of accidental harm, to show in the figure the ASD individuals' processing of accidental harm. Therefore, we replaced "Attempted Harm" with "Accidental Harm" in the top boxes, and we also changed accordingly the bottom boxes. The authors apologize for the mistake.

The original article has been reproduced with the correct image, originally it was published with the version of Figure 1 displayed here.

The original files have been updated.

\section{OPEN ACCESS}

Edited and reviewed by: Paola Molina

University of Turin, Italy

*Correspondence: Luca Surian

luca.surian@unitn.it

Specialty section: This article was submitted to Developmental Psychology, a section of the journal Frontiers in Psychology

Received: 06 October 2016 Accepted: 17 October 2016 Published: 27 October 2016

Citation:

Margoni F and Surian L (2016) Corrigendum: Mental State Understanding and Moral Judgment in Children with Autistic Spectrum Disorder. Front. Psychol. 7:1705. doi: 10.3389/fpsyg.2016.01705

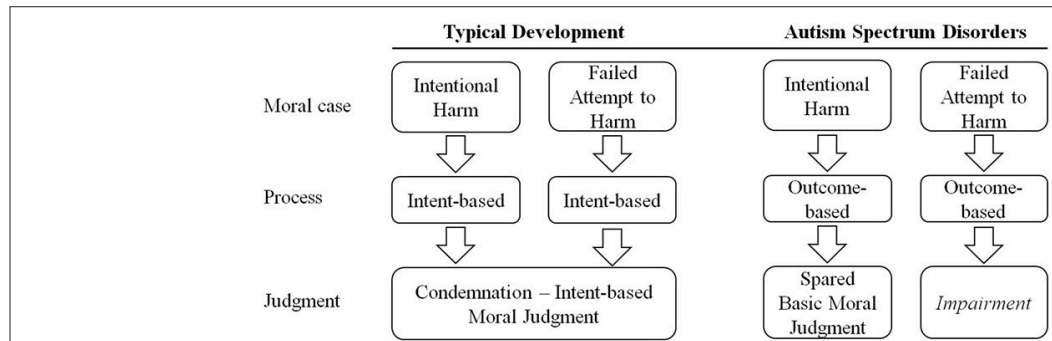

FIGURE 1 | A comparison of moral judgment in children with typical development and children with autism.

\section{AUTHOR CONTRIBUTIONS}

All authors listed, have made substantial, direct and intellectual contribution to the work, and approved it for publication.

Conflict of Interest Statement: The authors declare that the research was conducted in the absence of any commercial or financial relationships that could be construed as a potential conflict of interest.

Copyright (c) 2016 Margoni and Surian. This is an open-access article distributed under the terms of the Creative Commons Attribution License (CC BY). The use, distribution or reproduction in other forums is permitted, provided the original author(s) or licensor are credited and that the original publication in this journal is cited, in accordance with accepted academic practice. No use, distribution or reproduction is permitted which does not comply with these terms. 